\title{
Educação inclusiva nas políticas de avaliação institucional reflexos no contexto da Universidade Estadual de Goiás
}

Diessyka Fernanda MonTEIRO, Universidade Estadual de Goiás

Yara Fonseca de Oliveira e SILvA, Universidade Estadual de Goiás

$\mathrm{O}$ artigo trata das diretrizes para a educação inclusiva na educação superior e seu reflexo no planejamento, avaliação e resultados da autoavaliação institucional realizada na Universidade Estadual de Goiás. $\mathrm{O}$ objetivo geral foi verificar o alinhamento entre os princípios da educação inclusiva com as políticas de avaliação institucional, consolidadas no Relatório de Avaliação Institucional. A questão norteadora buscou responder em que medida as diretrizes da Educação Especial na perspectiva da educação inclusiva reflete nos documentos da avaliação interna da UEG? Na tentativa de realizar a crítica e apontar sugestões, o estudo realizado aplicou a metodologia de análise documental do Relatório Consolidado de autoavaliação do ciclo trienal (UEG, 2015-2017) produzido pela CPA/UEG com base no PDI (UEG/ 2010-2019). Concluiu-se que as diretrizes condutoras na elaboração da Lei Brasileira de Inclusão da Pessoa com Deficiência foram parcialmente agregadas às políticas de avaliação institucional da UEG.

PALAVRAS-Chave: Educação Especial e Inclusiva. Política de Avaliação. Autoavaliação da UEG. 
Educação inclusiva nas políticas de avaliação

\section{Introdução}

A Educação Inclusiva é um campo marcado por necessidades as quais devem ser examinadas sob diversas perspectivas para que novas práticas e posturas possam ser adotadas como valor social e educacional relevante. Repensar a inclusão e a alteridade implica em um remanejamento e uma reestruturação na própria lógica de gestão das universidades diante do imenso desafio de adotar um projeto institucional que incentive o exercício da alteridade.

Por meio deste estudo pretendemos contribuir com a análise das diretrizes para a Educação Inclusiva na educação superior e como elas refletem no planejamento, avaliação e resultados da autoavaliação institucional realizada na Universidade Estadual de Goiás (UEG). Isto porque, consideramos que a política de avaliação da educação superior é um dos dispositivos de gestão que pode contribuir no planejamento estratégico de programas especializados e na concretização das leis. E, portanto, entender se as pessoas com necessidades educacionais específicas estão tendo acesso ao conhecimento, o quanto este tem avançando na ampliação dos direitos e o que ainda precisa ser melhorado.

Para isto, realizamos a análise documental de diretrizes políticas de Educação Especial e Educação Inclusiva de Goiás, tais como: a Política Nacional de Educação Inclusiva na Perspectiva da Educação Especial; a Lei $\mathrm{n}^{0} 13.146$ - Lei brasileira de inclusão da pessoa com deficiência (LBI); a Constituição Federal (CF/1988); Lei de Diretrizes e Bases da Educação Brasileira (LDB 9.394/1996); e, o Plano Nacional da Educação (PNE, 2011-2020). A análise também considerou a Política de avaliação da educação superior (Sinaes, Lei 10.861) que orienta o Relatório Consolidado de Autoavaliação institucional da UEG/Anápolis (2015-2017) produzido pela Comissão Própria de Avaliação (CPA/UEG) com base no Plano de Desenvolvmento Institucional - PDI (UEG/ 2010-2019).

Neste estudo, dentre diversas inquietações a questão de interesse refere-se ao alinhamento entre os princípios da Educação Inclusiva com a política de avaliação institucional, consolidadas no Relatório de Avaliação Institucional da UEG. Por isso, buscamos responder em que medida as diretrizes da Educação Especial na perspectiva da educação inclusiva reflete nos documentos da avaliação interna da UEG? 
No intuito de refletir e buscar respostas, esse texto está estruturado em sessões nas quais: apresentamos uma síntese das leis, políticas e diretrizes que fundamentam a Educação Inclusiva com destaque para a educação superior; realizamos um breve esclarecimento sobre a política de avaliação da educação superior instituída pelos Sinaes (Lei 10.861/2004), com recorte nos critérios que tratam da inclusão e acessibilidade; e, por fim, analisamos o Relatório Consolidado de Avaliação Institucional da UEG (ano base 2018) e seus reflexos no âmbito institucional.

\section{Educação Inclusiva e a educação superior: legislação, alteridade e direito}

"Na era moderna, o outro tem deixado de ser um objeto de paixão para se converter num objeto de produção" (Skliar, 2003, p. 41).

A afirmação de Skliar é provocativa. Considerar o outro como 'objeto de produção' nos convida a repensar sobre o modo pelo qual conduzimos o estudo sobre o diferente, sem abrir mão dos princípios que fundamentam as relações de alteridade entre o eu e o exterior de mim mesmo, entre os outros com os outros.

Em outras palavras, pensar o processo de 'inclusão' exige um olhar para além das políticas, das nomeclaturas, das inovações educacionais, ou dos discursos sobre o diferente. Desse modo, é necessário compreender que não é o outro que precisa ser incluído, porque ele sempre esteve, mas são os representantes do lugar de fala da educação, da legislação, do Estado, que precisam ser observados, desvelados, pois o diferente também nos enxerga e vê para além dos discursos, às vezes, infinitos e medíocres (SKLIAR, 2003).

Essa mudança de percepção, na concepção de Skliar, seria o primeiro passo para a ruptura no campo educacional em relação ao pensamento ocidental de tomar o outro pelo próximo e não pelo que o outro realmente é. Nessa relação entre o igual e o diferente, "sem o outro não seríamos nada, não haveria a alteridade, porque o outro já não está em um tempo isolado (passado), mas aqui e em todas as partes; inclusive onde nossa pétrea mesmicidade não alcança ver" (SKLIAR, 2003, p. 41). Contudo, a solução não está apenas em elucidar essa diversidade. Não é reduzir a diferença ao definível ou nominável, mas é "a experiência viva de uma irrupção - da palavra e do olhar - que torna possível essas 
outras formas de alteridade" (SKLIAR, 2003, p. 44). O diverso e o diferente, à medida que se mostram, que se desvelam, irrompem com a construção homogênea construída por aqueles que se perturbam com os rostos daqueles. É na irrupção do outro que reside sua alteridade.

Ao mesmo tempo em que o outro não é o objeto de produção em si mesmo, o processo de inclusão é uma prática que precisa ser exercida por todos, bem como ser de responsabilidade daqueles que assistem (e produzem) as mudanças na universalização do acesso à educação. Algumas dessas mudanças podem ser observadas pelas diretrizes políticas direcionadas à educação na legislação federal.

Historicamente, a Constituição da República Federativa do Brasil passou, gradativamente, a incorporar os valores da Educação Inclusiva, na busca pela promoção de um Estado democrático, destinado a assegurar os direitos sociais, individuais, a igualdade e a justiça como valores supremos de uma sociedade fraterna, pluralista e sem preconceitos de forma a "promover o bem de todos, sem preconceitos de origem, raça, sexo, cor, idade e quaisquer outras formas de discriminação" (art. $3^{\circ}$ inciso IV). Ela constitui-se, portanto, em fundamentos de soberania, cidadania e dignidade da pessoa humana que visam construir uma sociedade livre, justa e solidária com extinção das desigualdades sociais e promoção do bem comum, sem preconceitos de raça, cor, sexo, idade ou quaisquer outras formas de discriminação (BRASIL, 1988, art. $3^{\circ}$ ). Com base nesse fundamento, a educação é um direito social atribuido a todos, devendo ser "promovida e incentivada com colaboração da sociedade, visando ao pleno desenvolvimento da pessoa para o exercício da cidadania e sua qualificação para o trabalho" (BRASIL, 1988, art. 205 , p. 86).

Por muito tempo a concepção de que a Educação Especial estava estritamente relacionada aos problemas de saúde dos alunos que apresentavam deficiência, resultou em práticas que enfatizavam exclusivamente a deficiência. Nesse sentido, houve um aperfeiçoamento da concepção de direitos das pessoas com deficiência que denota uma dimensão mais personalizada e social com a noção de que a pessoa, antes de sua deficiência, é um sujeito que deve ser valorizado, bem como é preciso reconhecer sua capacidade de ser agente ativo de suas escolhas, decisões e determinações sobre sua própria vida. Ao assinalar a autonomia e independência individuais das pessoas com deficiência, inclusive da liberdade delas fazerem suas próprias escolhas, reforça-se o princípio de vida independente para que possam participar ativamente 
das decisões relativas a programas e políticas públicas, principalmente as que lhes dizem respeito diretamente.

A Constituição Federal (1988) e as ações do movimento mundial pela inclusão, a Secretaria de Educação Especial vinculada ao Ministério da Educação (MEC), produziram e apresentaram a Política Nacional de Educação Especial na Perspectiva da Educação Inclusiva (PNEE), visando constituir políticas públicas promotoras de uma educação inclusiva para todos os alunos. A política na Perspectiva da Educação Inclusiva tem como objetivo:

[...] assegurar a inclusão escolar de alunos com deficiência, transtornos globais do desenvolvimento e altas habilidades/ superdotação, orientando os sistemas de ensino para garantir: acesso ao ensino regular, com participação, aprendizagem e continuidade nos níveis mais elevados do ensino; transversalidade da modalidade de educação especial desde a educação infantil até a educação superior; oferta do atendimento educacional especializado; formação de professores para o atendimento educacional especializado e demais profissionais da educação para a inclusão; participação da família e da comunidade; acessibilidade arquitetônica, nos transportes, nos mobiliários, nas comunicações e informação; e articulação intersetorial na implementação das políticas públicas (BRASIL, 2008, p. 14).

Observa-se neste objetivo que a Educação Especial tem início na Educação Infantil - período escolar em que se desenvolvem as bases necessárias para a formação e o desenvolvimento global - e estende-se até a educação superior, o que reforça o caráter permanente e constante dessa educação como uma modalidade de ensino que perpassa todos os níveis de ensino. O texto elucida quem são os alunos atendidos pela Educação Inclusiva, indicando aqueles com transtornos globais do desenvolvimento e altas habilidades/superdotação os quais devem receber atendimento pedagógico especializado e ter direito à acessibilidade arquitetônica que inclui eliminação das barreiras ambientais físicas nos espaços como a presença de rampas, banheiros adaptados, elevadores adaptados, piso tátil, entre outras.

Corroborando com este documento, a Meta 4 do Plano Nacional da Educação (PNE) apresenta entre seus princípios a universalização do atendimento escolar; a redução das desigualdades e a valorização da diversidade (BRASIL, 2015). Conforme esta meta, a universalização deve garantir a inclusão de todos dos grupos sociais com deficiência, com idades de 4 a 17 anos, transtornos globais do desenvolvimento (TGD) e 
altas habilidades ou superdotação. O segundo objetivo da meta 4 preconiza que o atendimento educacional direcionado a essas pessoas deve ocorrer por meio da educação inclusiva, ou seja, "preferencialmente na rede regular de ensino, com a garantia de sistema educacional inclusivo, de salas de recursos multifuncionais, classes, escolas ou serviços especializados, públicos ou conveniados" (BRASIL, 2015, p. 68).

$\mathrm{Na}$ educação superior, as diretrizes da política nacional de Educação Especial na perspectiva da Educação Inclusiva preveem a transversalidade da Educação Especial como estratégias que se efetivam por meio de ações que promovam o acesso, a permanência e a participação dos alunos.

Estas ações envolvem o planejamento e a organização de recursos e serviços para a promoção da acessibilidade arquitetônica, nas comunicações, nos sistemas de informação, nos materiais didáticos e pedagógicos, que devem ser disponibilizados nos processos seletivos e no desenvolvimento de todas as atividades que envolvem o ensino, a pesquisa e a extensão (BRASIL, 2008, p. 17).

Como propostas de ações para superar o desafio de garantir o acesso e permanência dos alunos com deficiência, foi instituído, em 2005, o Programa de acessibilidade na educação superior (Programa Incluir) com o objetivo de "promover ações para eliminar barreiras físicas, pedagógicas e de comunicação, a fim de assegurar o acesso e a permanência de pessoas com deficiência nas instituições federais de educação superior (IFEs)" (BRASIL, 2013). Este programa refletiu sobre a criação e a consolidação de núcleos de acessibilidade em várias IES. Na UEG inclui-se o Plano de promoção de acessibilidade e de atendimento diferenciado a portadores de necessidades especiais.

A Lei Brasileira de Inclusão da Pessoa com Deficiência 13.147/2015 define que:

[...] constitui direito da pessoa com deficiência, assegurados sistema educacional inclusivo em todos os níveis e aprendizado ao longo de toda a vida, de forma a alcançar o máximo de desenvolvimento possível de seus talentos e habilidades físicas, sensoriais, intelectuais e sociais, segundo suas características, interesses e necessidades de aprendizagem (BRASIL, 2015).

Sendo assim, a pessoa com deficiência tem o direito de acessar o sistema educacional, em específico a educação superior. 


\section{Reflexo da educação inclusiva na política de avaliação institucional da educação superior}

Mesmo diante das perspectivas para o atendimento educacional de alunos com deficiência, a garantia de acessibilidade e inclusão na educação superior é uma temática conflituosa que desperta incertezas sobre a real efetivação das legislações, dos programas e atendimento educacional especializado. Por isso, ainda são necessárias modificações nas legislações e acompanhamento no campo ${ }^{1}$ educacional para que, de fato, o acesso e permanência destes alunos sejam garantidos na educação superior.

No que se refere especificamente às universidades, a avaliação institucional ganhou reconhecimento legal com a implantação do Sistema Nacional de Avaliação da Educação Superior (Sinaes), instituído pela Lei 10.861, de 14 de abril de 2004, e pela Portaria Normativa MEC $\mathrm{n}^{\mathrm{O}}$ 40/2007, que tratam dos processos de regulação, avaliação e supervisão da educação superior no sistema federal de educação. Em conformidade com esta política, a Universidade Estadual de Goiás (UEG) adota a metodologia de avaliação institucional sugerida pela lei citada, bem como, as normatizações apresentadas pelas Notas Técnicas relacionadas com a avaliação institucional e a Resolução do Conselho Superior da UEG (CsU), n. 1, de 6 de fevereiro de 2014, que "Aprova o novo Regulamento da Comissão Própria de Avaliação da Universidade Estadual de Goiás (CPA/UEG)”.

Os princípios fundamentais do Sinaes que devem ser mantidos pelas instituições de educação superior são:

a) Melhoria da qualidade da educação superior;

b) Aprofundamento dos compromissos de responsabilidades sociais das instituições de educação superior, por meio da valorização de sua missão pública, da promoção dos valores democráticos, do respeito à diferença e à diversidade, da afirmação da autonomia e da identidade institucional;

$1 \mathrm{O}$ conceito de campo foi utilizado aqui na acepção de Bourdieu (2004) como um conjunto de espaço simbólico e estruturados de posições cujas propriedades dependem das posições nesses espaços. O campo específico da educação superior pressupõe confronto, tomada de posição, luta, tensão, poder, já que, de acordo com Bourdieu, os campos são formados por agentes, que podem ser indivíduos ou instituições, os quais criam os espaços e os fazem existir pelas relações que ali estabelecem. 
Educação inclusiva nas políticas de avaliação

institucional reflexos no contexto da Universidade

Estadual de Goiás

c) Afirmação da autonomia e identidade institucional;

d) Assegurar a participação do corpo discente, docente e técnicoadministrativo das instituições de educação superior, e da sociedade civil, por meio de suas representações.

e) Promover o autoconhecimento institucional por meio de suas atividades, cursos, programas, projetos e setores, considerando as diferentes dimensões institucionais.

f) Dar continuidade ao processo avaliativo.

(BRASIL, 2004).

Os referidos princípios retomam fundamentos já declarados nos arts. 3, 4, 214 da LDB/1996 que assegura condições de universalização do atendimento escolar; melhoria da qualidade do ensino; preservação da autonomia universitária; igualdade de condições para o acesso e permanência na escola; respeito à liberdade e apreço à tolerância. De modo geral, os fundamentos do Sinaes estão pautados na gestão democrática de ensino que valoriza a participação de todas as instâncias envolvidas nos processos decisórios da gestão educacional de modo que se efetive a transparência e a democracia. Entretanto, uma gestão democrática, cuja interface com a educação pode ser compreendida sob diferentes concepções, mostra-se conflituosa frente a uma sociedade impregnada de várias formas de seletividade social. A interrogação que se coloca é o que a universidade tem feito para fortalecer uma gestão democrática, considerando as vozes plurais daqueles que não estão à frente das tomadas de decisões? Esta é uma demanda da democracia que visa construir uma resposta conjunta para uma sociedade cada vez mais complexa.

É em torno desta complexidade que se constroem instrumentos, metodologias e técnicas capazes de avaliar e julgar todo um sistema cultural e social a partir de parâmetros éticos construídos coletivamente. Aqui entra a avaliação como um instrumento lógico de interpretação da realidade, na busca de desvelar a realidade educacional concreta, pensada, compreendida em seus mais diversos e contraditórios aspectos. Avaliação não deve ter um fim nela mesma, tampouco ser uma mera acumulação de dados, mas constitui o processo de determinar o valor das coisas. No contexto da gestão democrática, sua finalidade é fornecer recursos para gerar mudança de atitude em relação aos problemas enfrentados no campo educacional. 
Assim, a avaliação institucional envolve "a avaliação de um conjunto de programas oferecidos por uma instituição, além de uma avaliação da gestão como um todo, da publicidade, políticas, e assim por diante no nível da instituição" (SCRIVEN, 2018, p. 169). A autoavaliação ou avaliação interna, também se constituem como canais de comunicação da Instituição de Ensino Superior (IES), favorecendo o acesso de todos os segmentos da comunidade acadêmica (docentes, discentes, corpo técnico-administrativo, sociedade civil), e fomentando a manifestação da comunidade, gerando insumos para a melhoria da qualidade institucional.

Os processos de avaliação, regulação e supervisão da educação superior, de acordo com o Sinaes (pelo qual se submetem as instituições de educação superior e toda sua comunidade acadêmica e de cursos), firma-se com base em roteiros de avaliação, entre eles: a) Instrumento de Avaliação Institucional - roteiro para credenciamento e recredenciamento de instituições para ofertas de cursos presenciais ou na modalidade a distância; b) Relatórios de Autoavaliação Institucional realizada pelas próprias IES (CPA - Comissões Próprias de Avaliação).

No recorte deste estudo, realizamos as análises com base nos dois instrumentos de avaliação institucional: a) Instrumento de Avaliação Institucional (para credenciamento e recredenciamento de instituições para ofertas de cursos presenciais ou na modalidade a distância); e, b) Relatórios de Autoavaliação Institucional. O primeiro subsidia os atos que autorizam os cursos - autorização, reconhecimento e renovação de reconhecimento - nos graus de tecnólogo, de licenciatura e de bacharelado para a modalidade presencial e a distância, visando manter o controle e a qualidade da educação superior. O segundo, Relatório de autoavaliação, registra o ciclo de avaliação interna, cuja finalidade é diagnosticar e apontar as fragilidades e potencialidades institucionais com o propósito de estabelecer estratégias para cada situação específica. Esses instrumentos são complementares no processo de autoavaliação institucional e avaliação externa realizada pelo Sinaes.

A autoavaliação é coordenada pela CPA estabelecida por cada IES, desde dezembro de 2004. Segundo o Roteiro de Autoavaliação, proposto pelo Sinaes, a avaliação interna tem como principais objetivos:

[...] produzir conhecimentos, pôr em questão os sentidos do conjunto de atividades e finalidades cumpridas pela instituição, identificar as causas dos seus problemas e deficiências, aumentar a consciência pedagógica e capacidade profissional do corpo docente e técnico- 
administrativo, fortalecer as relações de cooperação entre os diversos atores institucionais, tornar mais efetiva a vinculação da instituição com a comunidade, julgar acerca da relevância científica e social de suas atividades e produtos, além de prestar contas à sociedade. Identificando as fragilidades e as potencialidades da instituição nas dez dimensões previstas em lei, a autoavaliação é um importante instrumento para a tomada de decisão e dele resultará um relatório abrangente e detalhado, contendo análises, críticas e sugestões (BRASIL, 2004).

Seguindo as recomendações do Sinaes a avaliação institucional interna da UEG tem o objetivo de levantar e analisar dados da realidade concreta de todos os setores e Unidades da UEG, assim como recomendar ações para solucionar os questionamentos e/ou fragilidades detectados nos projetos, nos quadros profissionais e no funcionamento ou execução das atividades cotidianas de ensino, pesquisa e extensão. As recomendações da CPA referem-se à contribuição para a superação de obstáculos da UEG para cumprir os compromissos firmados por essa instituição para garantir a qualidade acadêmica, em conformidade com o sentido que as ações institucionais públicas devem possuir.

De acordo com as competências descritas na legislação, cabe ao Instituto Nacional de Estudos e Pesquisas Educacionais Anísio Teixeira (Inep) a elaboração dos Instrumentos de Avaliação Institucional Externa Presencial e a Distância² (2017), a partir de diretrizes estabelecidas pelos órgãos do MEC. Por meio desse instrumento são definidos os eixos3 e os indicadores 4 no processo de construção dos parâmetros de qualidade do curso. $\mathrm{O}$ instrumento contempla as 10 dimensões, determinadas pelo art. $3^{\mathrm{o}}$ da Lei 10.861/2004 do Sinaes, agrupadas nas seguintes categorias:

2 Este Instrumento subsidia os atos autorizativos de cursos - autorização, reconhecimento e renovação de reconhecimento - nos graus de tecnólogo, de licenciatura e de bacharelado para a modalidade presencial e a distância. O documento na íntegra encontra-se no site: http://portal.inep.gov.br/instrumentos.

3 De acordo com a Lei $n^{0} 10.861$, no artigo $3^{0}$ da Lei do Sinaes ficaram definidas 10 dimensões obrigatórias para serem avaliadas nas Instituições de Educação Superior. Posteriormente, com a emissão da Nota Técnica $n^{0}$ 14/2014, emitida pelo Ministério da Educação (Mec), as dimensões foram agrupadas de acordo com 5 eixos, visando a facilitar a avaliação.

4 Indicadores são evidências concretas (quantitativas ou qualitativas) relativas a cada um dos grupos de fatos, acontecimentos, ou fenômenos que, de forma simples ou complexa, caracterizam a realidade dos múltiplos aspectos institucionais que retratam (conforme nota da Comissão própria de avaliação da UEG). 
1. a missão e o plano de desenvolvimento institucional (PDI);

2. a política para o ensino, a pesquisa, a pós-graduação e a extensão;

3. $\quad$ a responsabilidade social da instituição;

4. a comunicação com a sociedade;

5. $\quad$ as políticas de pessoal;

6. a organização e gestão da instituição;

7. a infraestrutura física;

8. o planejamento e a avaliação;

9. as políticas de atendimento aos estudantes;

10. a sustentabilidade financeira (BRASIL, 2004).

As dez dimensões estão agrupadas por afinidade em cinco eixos, com indicadores que apresentam elementos de avaliação e os respectivos critérios para sua análise e verificação. A leitura do instrumento buscou identificar os termos que se relacionam à educação inclusiva. Ao final do documento, disponibilizado em forma de glossário, identificamos cinco conceitos referentes ao apoio e atendimento à pessoa com deficiência:

a. Acessibilidade - "Possibilidade e condição de alcance para utilização, com segurança e autonomia, de espaços, mobiliários, equipamentos urbanos, edificações, transportes, informação e comunicação, inclusive seus sistemas e tecnologias, bem como de outros serviços e instalações abertos ao público, de uso público ou privados de uso coletivo, tanto na zona urbana como na rural, por pessoa com deficiência ou com mobilidade reduzida" (Lei 13.146/2015 - art. $3^{\circ}$, inciso I).

b. Acessibilidade digital - Uso de tecnologias que tornem a comunicação e o conteúdo virtual (ambientes de aprendizagem, ferramentas, correio eletrônico, fóruns de discussão, páginas web) acessíveis aos indivíduos que necessitem de interface específica, seja de forma autônoma ou assistida.

c. Apoio psicopedagógico - atendimento de apoio ao discente, que pode ser estendido a todos aqueles que participam da 
comunidade acadêmica, com o objetivo de avaliar, acompanhar e sanar dificuldades no processo ensino-aprendizagem, especificamente aquelas que levam ao impedimento da aquisição dos conhecimentos, habilidades e atitudes a serem desenvolvidas na formação discente.

d. Atendimento Educacional Especializado (AEE) - serviço da educação especial que "identifica, elabora, e organiza recursos pedagógicos e de acessibilidade, que eliminem as barreiras para a plena participação dos alunos, considerando suas necessidades específicas" (Revista da Educação Especial. v. 04. n 05. Brasília: SEESP, 2008. p. 15).

e. Inclusão - ações que visam a incluir os discentes nas atividades institucionais, objetivando oportunidades iguais de acesso e permanência, considerando-se não só a existência de deficiências, mas também diferenças de classe social, gênero, idade e origem étnica (BRASIL, 2017, p. 33-42).

O conceito de acessibilidade5 foi transcrito ipsis litteris da Lei 13.146/2015. Segundo Resende (2008), a acessibilidade é a ferramenta de serviços e produtos disponibilizados às pessoas com deficiência com base no princípio da igualdade. Sendo assim, a acessibilidade reflete ações pontuais na eliminação de barreiras, tanto físicas quanto digital e tecnológica, que visam criar condições diversificadas, respeitando as necessidades de cada pessoa. Desta forma, a acessibilidade é compreendida como uso de recursos capazes de agregar qualidade de vida, não somente às pessoas com deficiência, mas também aos idosos, crianças, gestantes, pessoas temporariamente com mobilidade reduzida (vítimas de fraturas e entorses), dentre outras.

O Atendimento Educacional Especializado (AEE) está previsto na $\mathrm{CF} / 1988$, no art. 208, inciso III, sob o mesmo princípio da igualdade, que sugere adequação dos recursos físicos e humanos para condições iguais de atendimento e com qualidade na prestação de serviços. Esse termo foi definido na Política Nacional de Educação Especial na Perspectiva da Educação Inclusiva (PNEE) e tem por finalidade identificar, elaborar e organizar recursos pedagógicos e de acessibilidade que:

$5 \mathrm{O}$ conceito de acessibilidade está mais detalhado no Decreto $\mathrm{N}^{\circ} 5.296$ de 2 de dezembro de 2004 que estabelece normas gerais e critérios básicos para a promoção da acessibilidade das pessoas portadoras de deficiência ou com mobilidade reduzida. 
[...] eliminem as barreiras para a plena participação dos alunos, considerando as suas necessidades específicas [...]. Esse atendimento complementa e/ou suplementa a formação dos alunos com vistas à autonomia e independência na escola e fora dela [...]. O atendimento educacional especializado disponibiliza programas de enriquecimento curricular, o ensino de linguagens e códigos específicos de comunicação e sinalização, ajudas técnicas e tecnologia assistiva, dentre outros. Ao longo de todo processo de escolarização, esse atendimento deve estar articulado com a proposta pedagógica do ensino comum (BRASIL, 2008, p. 16).

Por fim, o termo inclusão, no contexto da Educação Inclusiva, dá-se por meio do atendimento especializado e da Educação Especial. Segundo o Conselho Estadual de Educação de Goiás, por meio da Resolução n. 07, de 15 de dezembro de 2006, define a educação inclusiva como "um processo social, pedagógico, cultural, filosófico, estético e político de ações educativas, pedagógicas e administrativas voltadas para a inclusão" (art. $1^{\circ}$ ), e, insere a educação especial no âmbito da educação inclusiva.

\section{Perspectiva da inclusão nos relatórios de avaliação institucional da Universidade Estadual de Goiás}

Após considerar os conceitos fundamentados na Educação Inclusiva e seu reflexo no Instrumento de Avalição, vejamos de que modo estes conceitos estão materializados nos indicadores apresentados pelo Sinaes (indicados na Tabela 1). Em seguida, comparamos os mesmos indicadores à proposta do PDI (UEG, 2009-2019) da UEG e às recomendações da Comissão Própria de Avaliação no Relatório Consolidado da UEG no ciclo (2015-2017). Essa análise foi fundamentada, sobretudo, nas disposições do art. 208, inciso III da Constituição Federal, na legislação Brasileira de Inclusão da Pessoa com Deficiência, na Lei 13.146/2015, e nos arts. 58 e 59 da LDB 9394/96. 
Tabela 1 - Eixos de Autoavaliação (Sinaes 2017)

\begin{tabular}{|c|c|c|c|}
\hline EIXOS & INDICADORES & $\begin{array}{l}\text { CRITÉRIO DE } \\
\text { ANÁLISE }\end{array}$ & DESCRIÇÃO \\
\hline \multirow{3}{*}{$\begin{array}{l}\text { Eixo } 2 \\
- \\
\text { Desenv } \\
\text { olvimen } \\
\text { to } \\
\text { Instituc } \\
\text { ional }\end{array}$} & Indicador 2.2 & $\begin{array}{l}\text { Planejamento } \\
\text { d i d á t i c o - } \\
\text { instrucional e } \\
\text { polític a d e } \\
\text { en sino d e } \\
\text { graduação e de } \\
\text { pós-graduação. }\end{array}$ & $\begin{array}{l}\text { Há alinhamento entre o PDI e a política } \\
\text { de ensino, considerando os métodos e as } \\
\text { té c nicas didático - pe da gógica s, } \\
\text { m et od olog ias que favo recem o } \\
\text { atendimento educacional especializado } \\
\text { (...) que se traduz nas práticas de ensino } \\
\text { de graduação e de pós-graduação [...]. }\end{array}$ \\
\hline & Indicador 2.4 & $\begin{array}{l}\text { P o lít i c a s } \\
\text { institucionais } \\
\text { voltad a s à } \\
\text { valorização da } \\
\text { diversidade (...) e } \\
\text { ações afirmativas } \\
\text { d e d e fes a e } \\
\text { promoção dos } \\
\text { D i r e i t o s } \\
\text { Humanos e da } \\
\text { igualdade étnico- } \\
\text { racial. }\end{array}$ & $\begin{array}{l}\text { O PDI possui políticas institucionais que } \\
\text { se traduzem em ações voltadas à } \\
\text { valorização da diversidade, (...) e em } \\
\text { ações afirmativas de defesa e promoção } \\
\text { dos Direitos Humanos e da igualdade } \\
\text { étnico-racial, de modo transversal aos } \\
\text { cursos ofertados [...]. }\end{array}$ \\
\hline & Indicador 2.5 & $\begin{array}{l}\text { P o lit i c a s } \\
\text { institucion ais } \\
\text { voltad a s a o } \\
\text { desenvolvimento } \\
\text { econômico e à } \\
\text { responsabilidade } \\
\text { social. }\end{array}$ & $\begin{array}{l}\text { Há alinhamento entre o PDI e as políticas } \\
\text { institucionais para o desenvolvimento } \\
\text { econômico e social, considerando a } \\
\text { melhoria das condições de vida da } \\
\text { população e as ações de inclusão e } \\
\text { empreendedorismo, articulando os } \\
\text { objetivos e valores da IES e a promoção } \\
\text { de ações reconhecidamente exitosas ou } \\
\text { inovadoras. }\end{array}$ \\
\hline \multirow[t]{3}{*}{$\begin{array}{c}\text { Eixo } 3 \\
- \\
\text { Política } \\
\text { s } \\
\text { Acadêm } \\
\text { icas }\end{array}$} & Indicador 3.11 & $\begin{array}{l}\text { Polític a d e } \\
\text { atendimento aos } \\
\text { discentes }\end{array}$ & $\begin{array}{l}\text { A política de atendimento aos discentes } \\
\text { contempla programas de acolhimento e } \\
\text { permanência do discente, programas de } \\
\text { a c essibilidade, (...) e a p o i o } \\
\text { psicopedagógico, apresenta uma } \\
\text { instância que permite o atendimento } \\
\text { discente em todos os setores pedagógico- } \\
\text { administrativos da instituição e promove } \\
\text { outras ações reconhecidamente exitosas } \\
\text { ou inovadoras. }\end{array}$ \\
\hline & Indicador 5.2 & Salas de aula & $\begin{array}{l}\text { As salas de aula atendem às necessidades } \\
\text { institucionais, considerando a sua } \\
\text { adequação a acessibilidade [...]. }\end{array}$ \\
\hline & Indicador $5 \cdot 3$ & Auditório(s) & $\begin{array}{l}\mathrm{O}(\mathrm{s}) \text { a uditório }(\mathrm{s}) \text { a ten } \mathrm{de}(\mathrm{m}) \text { à } \mathrm{s} \\
\text { necessidades institucionais, considerando } \\
\text { a acessibilidade }[. . .] \text {. }\end{array}$ \\
\hline
\end{tabular}




\begin{tabular}{|c|c|c|c|}
\hline \multirow{8}{*}{$\begin{array}{l}\text { Eixo } 5 \\
\quad- \\
\text { Infraest } \\
\text { rutura }\end{array}$} & Indicador 5.4 & $\begin{array}{ll}\mathrm{S} \text { a l a } & \mathrm{d} \mathrm{e} \\
\text { professores }\end{array}$ & $\begin{array}{l}\text { As salas de professores atendem às } \\
\text { necessidades institucionais, considerando } \\
\text { a sua adequação às atividades, a } \\
\text { acessibilidade [...]. }\end{array}$ \\
\hline & Indicador 5.5 & $\begin{array}{l}\text { Espaços para } \\
\text { atendimento aos } \\
\text { discentes }\end{array}$ & $\begin{array}{l}\text { Os espaços para atendimento aos } \\
\text { discentes atendem às necessidades } \\
\text { institucionais, considerando a sua } \\
\text { adequação às atividades, a acessibilidade } \\
\text { [...]. }\end{array}$ \\
\hline & Indicador 5.6 & $\begin{array}{l}\text { E s p a ços d e } \\
\text { convivência e de } \\
\text { alimentação }\end{array}$ & $\begin{array}{l}\text { Os espaços de convivência e de } \\
\text { alimentação atendem às necessidades } \\
\text { institucionais, considerando a sua } \\
\text { adequação às atividades, a acessibilidade } \\
\text { [...]. }\end{array}$ \\
\hline & Indicador 5.7 & $\begin{array}{l}\text { Laboratórios, } \\
\text { a mbientes e } \\
\text { cenários para } \\
\text { p rát i c a s } \\
\text { didát icas : } \\
\text { infraestrutura } \\
\text { física }\end{array}$ & $\begin{array}{l}\text { Os laboratórios, ambientes e cenários } \\
\text { para práticas didáticas atendem às } \\
\text { necessidades institucionais, considerando } \\
\text { a sua adequação às atividades, a } \\
\text { acessibilidade [...]. }\end{array}$ \\
\hline & Indicador 5.9 & $\begin{array}{l}\text { B ibli o te cas: } \\
\text { infraestrutura }\end{array}$ & $\begin{array}{l}\text { A infraestrutura para bibliotecas atende } \\
\text { às necessidades institucionais, apresenta } \\
\text { acessibilidade, (...) fornece condições } \\
\text { pa ra a tendi im en to ed u c a ci o n a l } \\
\text { especializado [...]. }\end{array}$ \\
\hline & Indicador 5.11 & $\begin{array}{l}\text { Salas de apoio de } \\
\text { informática ou } \\
\text { e s } \mathrm{r} \mathrm{u} \mathrm{t} \mathrm{r} \text { a } \\
\text { equivalente }\end{array}$ & $\begin{array}{l}\text { As salas de apoio de informática ou } \\
\text { estrutura equivalente atendem às } \\
\text { necessidades institucionais, considerando } \\
\text { (...) a acessibilidade (incluindo recursos } \\
\text { tecnológicos transformadores) [...]. }\end{array}$ \\
\hline & Indicador 5.12 & $\begin{array}{l}\text { I n s t a l a ç õ e s } \\
\text { sanitárias }\end{array}$ & $\begin{array}{l}\text { As instalações sanitárias atendem às } \\
\text { necessidades institucionais, considerando } \\
\text { a sua adequação às atividades, (...) a } \\
\text { acessibilidade, [...]. }\end{array}$ \\
\hline & Indicador 5.17 & $\begin{array}{l}\text { Recursos de } \\
\text { tecnologias de } \\
\text { informação e } \\
\text { comunicação }\end{array}$ & $\begin{array}{l}\text { Os recursos de tecnologias de informação } \\
\text { e comunicação asseguram a execução do } \\
\text { PDI, viabilizam as ações acadêmico- } \\
\text { a d minis trativa s, ga r a n t e m a } \\
\text { acessibilidade comunicacional [...]. }\end{array}$ \\
\hline
\end{tabular}

Fonte: BRASIL, 2017, [adaptado].

No eixo 2 - Desenvolvimento Institucional - o Sinaes considera as políticas institucionais e o planejamento didático voltadas à valorização da diversidade, as ações afirmativas em defesa dos Direitos 
Humanos, o atendimento educacional especializado, e ações de inclusão. No que se referem às políticas institucionais direcionadas ao aluno com deficiência, o Plano de Desenvolvimento Institucional da UEG (2009-2019) não menciona políticas de ensino, políticas didáticopedagógicas, ou metodologias específicas que apontem para um atendimento educacional especializado ou ações de inclusão para os alunos com deficiência. Logo, com base nos indicadores (2.2), (2.4) e (2.5), não estabelece em seu PDI (UEG, 2009-2019), metas, objetivos, ações e valores que atenda a educação inclusiva. Na perspectiva da Educação Inclusiva, incluir significa oferecer condições pedagógicas, didática, arquitetônica, programas e atividades que garantam o acesso de todos os alunos. "Incluir é propiciar a todos os alunos novas possibilidades de crescer e desenvolver" (SANTOS e REIS, 2016, p. 333).

Um dos motivos que levam ao afastamento das ações afirmativas em defesa do aluno com deficiência é a falta de representatividade na condução do processo avaliativo. Esta afirmação pode ser percebida nos próprios resultados e conclusões do Relatório Consolidado da UEG (2015-2017), no qual observamos recomendações ao eixo 2, que referemse à reformulação do PDI com a participação de todos os segmentos ou outras representações de interesse universitário, ou seja, ter maior representatividade no processo de (re)elaboração das metas e ações no PDI. Nesse sentido, retoma-se a dificuldade de por em prática aquilo que convencionamos de alteridade. Há dificuldade de se colocar no lugar do outro e representá-lo, sendo apenas o eu fragmentado. Ainda que a experiência da alteridade seja a garantia de sermos antirradicais e de nos despir do ego de sermos nós mesmos, ela mostra ser uma relação conflituosa presente no próprio eu "que quer se afirmar como uno em um mundo fragmentado, onde o reconhecimento da diferença parece ser uma perigosa ameaça” (FURTADO, 2012, p.2).

Aqui caberia refletir se o 'discente' poderia ser o representante de todos os alunos (independentemente das múltiplas religiões, etnias, gêneros, classes sociais, deficiências), ou se, pela dificuldade em perceber o outro, deveria incluir as 'sub-representações discentes' a fim de garantir o direito de todos e uma convivência democrática e igualitária entre diferentes grupos. Na percepção de Furtado (2012), contemplar a diversidade e a diferença na educação é o primeiro passo para desconstruir a concepção cartesiana de homem fragmentado. A possibilidade de pensar o humano numa perspectiva histórico-social, de forma dialética, é um modo de mudar o olhar e o discurso sobre o outro e 
construir uma pedagogia da alteridade ${ }^{6}$. Assim, a prática de representação nas instâncias de gestão, pensada com base na ideia de alteridade, é realizada na relação entre diferentes sujeitos, os quais possuem valores e projetos também diferenciados. Contudo, é no processo interativo que ocorre a compreensão dos contextos de sujeitos plurais.

Uma prática de avaliação institucional adequada aos princípios de alteridade deve seguir o modelo de avaliação reflexivo-participativos7. Nesse modelo busca-se um aprendizado coletivo, compartilhado, produzido em processos interativos, pelo qual "o tratamento das informações e dados coletados ocorrem com diálogo, recuo crítico, e uma reflexão menos apaixonada das práticas, com explicitação das contradições no nível das ações-reações" (GATTI, 2014, p. 18). A avaliação participativa aponta para o estreitamento nas relações interpessoais, o que sinaliza o desafio da qualificação de gestores com boa articulação, empatia e interação entre os participantes.

[a falta de processos socioafetivo-culturais] é uma das razões pelas quais tantos programas que visam mudanças cognitivas, de práticas, de posturas, não se mostram efetivos. [a] centralização apenas nos aspectos cognitivos individuais esbarra nas representações sociais e na cultura de grupos. Em decorrência disso, é muito simplista a noção de que o aumento e melhoria no rol de conhecimentos informativos adquiridos individualmente serão suficientes para melhorar ou modificar conceitos e práticas ligadas ao trabalho profissional de gestores ou professores (GATTI, 2014, p. 21).

Em síntese, sugere-se como respostas ao desafio de direcionar os objetivos e valores desenvolvidos pelos mecanismos e programas de avaliação institucional o modelo de avaliação reflexivo-participativas, desde que seja considerada a intencionalidade das ações, o favorecimento das relações interpessoais, de formas coletivas e

6 Termo cunhado a partir do pensamento de Levinas que consiste na defesa de outra modalidade pedagógica, outro modo de ensino, fundada no acolhimento e na abertura ao ensinamento proveniente da alteridade, como condição ético-crítica do saber. Ver mais no estudo de Alves e Ghiggi (2012).

7 Gatti (2014, p. 17, apud GATTI, 2006, p. 196) descreve quatro possibilidades de modelos para avaliação institucional: a) modelos descritivos; b) modelos descritivos-analíticos; c) modelos reflexivo-interpretativo; d) modelos reflexivos-participativos. Embora nenhum modelo excluí o outro, onde todos se complementam, há uma valorização no último modelo por contemplar ações coletivas em todo o processo de planejamento. 
participativas do trabalho firmados em processo contínuo de autoanálise e reflexão.

No eixo 3 , referente às políticas acadêmicas de acolhimento e permanência do discente e programas de acessibilidade, o PDI (UEG, 2009-2019, p. 53) indica, na Política de Extensão, uma ação de apoio socioeconômico e de permanência na UEG, "destinado aos acadêmicos cotistas, segundo a Lei Estadual N. 14.832/2004 (oriundos da rede pública de educação básica, negros, indígenas e portadores de deficiências)". Portanto, atende o indicador (3.11) e menciona os alunos com deficiências. Ressalta-se que a política de atendimento aos discentes, conta com o Programa de apoio pedagógico e financeiro e Bolsa Permanência, previsto no PDI, o qual se estende a todos os acadêmicos da UEG, objetivando oferecer-lhes apoio socioeconômico, regulamentado pelo Plano de Assistência Estudantil (PAE), mas segundo as condições sociais e econômicas do discente.

$\mathrm{Na}$ autoavaliação, o eixo 3, política de atendimento ao discente, é o primeiro (e um dos poucos) a referendar medidas que objetivem eliminar desigualdades ou garantir igualdade de oportunidades com a participação dos estudantes da UEG em programas e/ou projetos de inclusão social, inclusão digital e ações afirmativas, realizados pelo Centro de Ensino e Aprendizagem em Rede (CEAR) ou por outras unidades institucionais (Câmpus ou Adm. Central). Desse modo, os itens recomendados na pesquisa de autoavaliação reforçam o apoio voltado para as bolsas estudantis (revisão de valores e critérios de concessão das mesmas); a construção de restaurante universitário nos Câmpus; a construção/aluguel de casa na qual os(as) estudantes que necessitam morar/pernoitar em dias letivos; a viabilização de intercâmbios culturais/estudantis custeados pela instituição/Estado; apoio estrutural para a criação de centros acadêmicos nos Câmpus e de diretório estudantil na Universidade Estadual de Goiás. Logo, nota-se que os interesses do grupo majoritário de discentes conduzem o foco das necessidades, sobrepondo o cosmopolitismo ${ }^{8}$.

Distante de uma orientação que inclua e promova acessibilidade dos alunos com deficiência, as recomendações apresentadas no Relatório Consolidado (2015-2017) quanto à responsabilidade social da UEG junto

8 Boaventura Santos (2009) considera cosmopolitismo um conjunto vasto e heterogêneo de movimentos que partilham a luta contra a exclusão e a discriminação social produzidos pelos processos dominantes de globalização. Cosmopolitismo é a solidariedade transnacional entro grupos explorados, oprimidos ou excluídos pela globalização hegemônica. 
à comunidade, é uma percepção estritamente capitalista do fomento de programas ou projetos que envolvam:

[...] ações de cooperativismo, de geração de emprego e renda, bem como de economia solidária, acompanhados de estratégias eficazes de divulgação para a comunidade local; e, criação de cursos para o atendimento da vocação dos municípios nos quais os Campus estarão inseridos (CPA, 2015-2017).

Conclui-se que, no eixo 3, há um distanciamento da ideia original na política de atendimento ao discente - eliminar desigualdades e favorecer a inclusão com apoio psicopedagógico - com a 'solução' apresentada - ações de cooperativismo, de geração de emprego e renda, bem como de economia solidária, etc. A solução distancia-se ainda mais dos princípios dos Direitos Humanos que é considerado fundamental no desenvolvimento das políticas acadêmicas (eixo 3), em especial nas políticas de atendimento aos discentes. Observar os dados, e a narrativa construída no Relatório de autoanálise da universidade, confirma a crítica apresentada por Santos (2009) sobre as tensões dialéticas das políticas progressistas e emancipatórias no contexto de um mundo globalizado, por um lado, e da fragmentação social, cultural e política, de outro,

[...] a complexidade dos Direitos Humanos reside em que eles podem ser concebidos e praticados, quer como forma de localismo globalizado, quer como forma de cosmopolitismo, ou, por outras palavras, quer como globalização hegemônica, quer como globalização contra hegemônica. (SANTOS, 2009, p. 13).

A globalização seria "o processo pelo qual determinada condição ou entidade local estende a sua influência a todo o globo e, ao fazê-lo, desenvolve a capacidade de designar como local outra condição social ou entidade rival" (SANTOS, 2009, p. 12). Assim, os Direitos Humanos trariam uma concepção contraditória, pois, de um lado, assenta-se em princípios e valores ocidentais hegemônicos, mas de outro pode operar como comospolismo, mas somente se esse for reconhecido como multiculturais, conforme afirma Santos (2009). Nesta perspectiva, uma avaliação institucional que atenda aos princípios da Educação Inclusiva (cosmopolita) precisa ampliar o diálogo cultural, considerando que cada cultura carrega versões diferentes de dignidade humana, igualdade e diferença. 
Por fim, o eixo 5, infraestrutura, é o mais extenso, incluindo um maior número de indicadores. Entretanto, todos relacionados à acessibilidade dos espaços físicos. A infraestrutura é considerada na Lei $13.146 / 2015$ - art. $3^{\circ}$, inciso I, como um dos deveres do poder público para assegurar a autonomia e promover segurança às pessoas com deficiência ou mobilidade reduzida.

Quanto à promoção de acessibilidade e de atendimento diferenciado a pessoas com deficiência, o PDI (UEG, 2009-2019), propôs um programa de acessibilidade de acordo com a norma NBR 9050:2004 (Acessibilidade a edificações, mobiliário, espaços e equipamentos urbanos) para as suas instalações, com adequação dos espaços para atendimento diferenciado dentro das Unidades Universitárias. Esse programa de acessibilidade tem como objetivos:

Identificar as barreiras existentes nos prédios da UEG, avaliar a acessibilidade e propor "adequação nos edifícios", sugerindo, assim, locais acessíveis para pessoas com mobilidade e percepção reduzidas, ou seja, pessoas com deficiências e limitações temporárias ou permanentes, bem como idosos, gestantes, obesos e pessoas com outros tipos de necessidades especiais (PDI/UEG, 2009-2019, p. 112-113).

Segundo relatado no próprio PDI (UEG, 2009-2019), o estudo de acessibilidade nos prédios das Unidades Universitárias, identificou dois tipos de soluções para as necessidades encontradas: em alguns prédios a implantação de rampas, e, em outros a implantação de elevador. Reforçou que as Unidades Universitárias construídas recentemente Ceres, Minaçu, Palmeiras de Goiás e Pirenópolis - já possuem alguma forma de acessibilidade para as pessoas com deficiência.

Este eixo referente à acessibilidade arquitetônica tem maior representatividade no Relatório da CPA. De acordo com os dados apresentados no Relatório Consolidado (2015-2017), 45\% dos respondentes caracterizaram a infraestrutura Física dos Câmpus como ótima ou boa, sendo considerado um percentual considerável. Segundo o Relatório, os gestores da Administração Central avaliaram com mais de 75\% de aprovação, já os docentes efetivos do Câmpus aparecem com a menor taxa de aprovação, com menos de 40\%. Entretanto, o maior número de críticas quanto à infraestrutura gira em torno da falta de acessibilidade para as pessoas com algum tipo de deficiência física. Ou seja, ainda que estabelecido em lei e em programas de acessibilidade, o direito a acessibilidade não foi completamente alcançado. 
Esse foi um dos poucos eixos que não apontou quaisquer recomendações ou proposta de melhoria referente à acessibilidade. Trata-se de uma questão problemática a ser analisada, pois conforme estudo, nesse documento não há previsão orçamentária específica para a Educação Inclusiva. Apenas de modo amplo, o PDI inclui orçamentos para Macroações como - construção, ampliação, reforma e adequação das instalações físicas da Universidade; estruturação do mobiliário e equipamentos e desenvolvimento tecnológico. Possivelmente, a fiscalização do desenvolvimento do programa de acessibilidade de acordo com a norma NBR 9050/2004, conforme previsto no Plano Institucional esteja a cargo do Conselho Universitário, conforme previsto no Estatuto da UEG, art.17:

São atribuições do Conselho Universitário, segundo Estatuto da UEG, art. 17: II. aprovar o plano de desenvolvimento da Universidade, elaborado com base no orçamento da instituição e segundo as diretrizes específicas estabelecidas pelo Conselho Curador da Fundação, bem como acompanhar periodicamente a sua execução (UEG, 2009-2019, p. 89).

Sabe-se que os recursos destinados à educação interferem na qualidade dos serviços prestados como na infraestrutura, qualificação dos profissionais da educação, elaboração dos programas e ações institucionais, sobretudo, quando voltada para inclusão, pois a disputa por repasses depende de quem participa da discussão. Só com a elevação substancial dos recursos aplicados na Educação Inclusiva será possível corrigir as desigualdades e melhorar a qualidade educacional.

O desafio para o repasse a esta área específica da educação se inicia na distribuição orçamentária do Estado de Goiás que designa apenas 2\% (dois por cento) do orçamento estadual para a UEG, com repasses em duodécimos mensais, garantindo-lhe autonomia financeira. Conforme o PDI (UEG, 2009-2019), as receitas orçamentárias da Universidade são provenientes de recursos do tesouro estadual, de recursos próprios e de recursos provenientes de convênios.

Os estudos realizados por Monlevade (2007) referente ao Fundo de Manutenção e Desenvolvimento da Educação Básica e de Valorização dos Profissionais da Educação (Fundeb) e a Educação Especial ajuda a elucidar o descompasso vivenciado pela Educação Inclusiva no Ensino Superior. O autor explica que a Educação Especial inclusiva chega a ter gastos três vezes mais altos se comparado à educação convencional, o que implica em uma maior disputa pelos recursos. Também cita que as 
Educação inclusiva nas políticas de avaliação

institucional reflexos no contexto da Universidade

Estadual de Goiás

políticas de atendimento às pessoas com deficiência concorrem com os recursos já destinados à saúde e à assistência social. Outro fator que dificulta a disputa por repasses públicos à educação especializada é histórico. Isto porque a presença constante de comunidades filantrópicas e entidades comunitárias, tais como a Associação de Pais e Amigos dos Excepcionais (APAE) e Pestalozzi, tem oferecido serviço especializado com repasses de fundo público e privado. Portanto, a solução seria a implantação de uma política de financiamento que incentive a presença não apenas do Estado, mas também Federal que garanta a expansão e continuidade do atendimento especializado na Educação Inclusiva.

Caminhar para além dos desafios orçamentários no contexto do globalismo econômico e político significa assumir uma mudança de consciência institucional com enfrentamento às desigualdades sociais, pautado no respeito à diversidade.

\section{Considerações Finais}

Em direção aos últimos apontamentos, cabe ressaltar que a análise realizada foi no âmbito institucional da UEG, tendo como referências o Plano de Desenvolvimento Institucional (PDI/UEG, 2009-2019) e o Relatório Consolidado de Autoavaliação Institucional da Universidade Estadual de Goiás (2015-2017), ambos documentos são abertos e disponibilizados no site oficial da IES. Outros documentos foram consultados como o Projeto Pedagógico Institucional (PPI) que reforça os princípios das Políticas de Ação Inclusiva para Pessoas com Deficiência e ou Mobilidade Reduzida, e indica uma ação: "reservar nos seus Processos Seletivos a porcentagem exigida de vagas para deficientes físicos" (UEG, PPI, 2011-2019). Não realizamos, portanto, um recorte específico nos cursos e em seus respectivos Projetos Pedagógicos dos Cursos (PPCs).

Para uma análise mais detalhada do atendimento educacional especializado, futuras pesquisas poderão comparar os princípios legais da Educação Inclusiva com as diretrizes do Projeto Pedagógico de Curso (PPC) ou as Diretrizes Curriculares Nacional (DCNs). Todavia, consideramos que o PDI tem sido o parâmetro de referência no processo de autoavaliação e de roteiro estratégico para que as metas, objetivos e valores da IES estejam articulados de forma coerente com os princípios do Direito Humano, da inclusão e da diversidade. 
Sendo o PDI o principal documento de referência para a autoavaliação institucional da UEG, observamos que há poucas políticas voltadas para o atendimento de alunos com deficiência e pouca consideração ao que estabelece a Lei 13.146/2015, art. 28, inciso III:

[...] projeto pedagógico que institucionalize $o$ atendimento educacional especializado, assim como os demais serviços e adaptações razoáveis, para atender às características dos estudantes com deficiência e garantir o seu pleno acesso ao currículo em condições de igualdade, promovendo a conquista e o exercício de sua autonomia (BRASIL, 2015).

O primeiro desafio ao gerar informações, por meio de instrumento teórico-metodológico de gestão, que resulte em uma análise crítica dos programas da Educação Inclusiva, consiste na clareza dos princípios - ético, político e filosófico - norteados por paradigmas que descentraliza a reflexão filosófica do possível centro predominante. Os conceitos e valores que norteiam as ações institucionais precisam estar explicitamente declaradas em seu Projeto Pedagógico Institucional e colocadas como valor institucional a interdiscursividade das diversas vozes pelo contínuo contraste com o "outro" e o constante aprender de suas cosmovisões e experiências históricas, procurando romper com a postura hermenêutica reducionista do capital.

Observamos que, em certa medida, a dificuldade do Relatório Consolidado da UEG de refletir sob tal paradigma, considerando que os instrumentos norteadores da avaliação não carregam na linguagem, no discurso e nas propostas uma postura interdiscursiva, de interação, que possibilite a compreensão cabal das diferenças e da diversidade cultural humana. Contraditoriamente, a linguagem representada nos documentos institucionais reforça o pensamento dominante do Estado liberal, centralizado na lógica do Eu que busca representar o diferente.

Sugere-se que os conceitos e princípios da Educação Inclusiva sejam mais articulados no PDI, pois como observa Clot (2006), a elaboração de um gênero textual, neste caso o Projeto Institucional, materializa as ações de um grupo em um tempo histórico. Assim, o gênero textual serviria de 'rascunho social' para esboçar as relações dos homens entre si para agir sobre o mundo. Ainda que o gênero por si mesmo não altere um comportamento hostil e preconceituoso, ele carrega normativas e descrições que nos dizem de que modo devemos agir em contextos específicos; como bem aumentar a consciência no momento de problematizar as ações institucionais na perspectiva da 
Educação inclusiva nas políticas de avaliação

inclusão junto aos gestores. A partir desta reformulação no PDI e PPI, a Comissão Própria de Avaliação pode realizar, com base nos documentos, um acompanhamento dos alunos com deficiência, garantindo que todos os indicadores de qualidade previstos no processo de autoavaliação institucional, além daqueles já previstos na Lei de Inclusão, os contemplem.

Essa reformulação pode surgir no próprio micro das relações. Ou seja, a Comissão Própria de Avaliação (CPA) pode convidar um dos alunos com deficiência para representar a comunidade nos órgãos gestores, abrindo espaço para outras vozes e história. Incluir diferentes comunidades no processo de planejamento da avaliação poderia resultar em mais direitos para a Educação Inclusiva e maior fiscalização das conquistas adquiridas na universidade. Outra contribuição pode surgir da comunidade especializada, nas quais grupos de pesquisadores no campo da Educação Inclusiva podem atuar juntamente com as CPAs durante o processo de avaliação institucional, propondo um roteiro de questionário e contribuindo nas reflexões e discussão dos resultados apresentado no Relatório Institucional.

Por fim, quanto à questão norteadora, se o pressuposto de inclusão e diversidade estão refletidos nas políticas de avaliação institucional, percebemos que as diretrizes que conduziram a elaboração da Lei Brasileira de Inclusão da Pessoa com Deficiência foram parcialmente agregadas às políticas de avaliação institucional. A análise das legislações brasileiras estabelece normativas que viabilizam a acessibilidade e permanência de alunos com deficiência principalmente, como detalhado na análise, o eixo 5, de infraestrutura, foi o que mais priorizou a inclusão com o fomento de alteração nos espaços, mobiliários, edificações e equipamentos como meio de assegurar o bemestar e a permanência de pessoas com mobilidade reduzida. No entanto, sabemos que a normatização e o direito por si só não promovem mudanças. Na forma como a Educação Inclusiva tem sido predominante avaliada e planejada, dimensões específicas que contribuiriam para a inclusão, dentre elas: o planejamento e sustentabilidade financeira, missão e valores institucionais redefinidos sob novos paradigmas educacionais e políticas acadêmicas de atendimento aos discentes com deficiência, precisam ainda ser viabilizados a partir de uma escuta mais sensível da CPA pelos alunos com deficiência. 


\section{Referências}

BOURDIEU, Pierre. Os usos sociais da ciência: por uma sociologia clínica do campo científico. São Paulo: UNESP, 2004.

BRASIL. Constituição da República Federativa do Brasil: texto constitucional promulgado em 5 de outubro de 1988, com as alterações adotadas pelas Emendas constitucionais nos 1/1992 a 99/2017, pelo decreto legislativo $\mathrm{n}^{0}$ 186/2008 e pelas Emendas constitucionais de revisão nos 1 a 6/1994. 53 ed. Brasília: Câmara dos Deputados, Edições Câmara, 2019. p. 167.

BRASIL. Lei de Diretrizes e Bases da Educação Nacional, LEI No 9.394, 20 de dezembro de 1996. Disponível em: http://www.planalto.gov.br/ ccivil_03/leis/L9394.htm Acesso em 17/05/2020.

BRASIL. Lei n. 10.861, de 14 de abril de 2004. Institui o Sistema Nacional de Avaliação da Educação Superior - SINAES e dá outras providências.

BRASIL. Lei $\mathrm{N}^{\circ}$ 13.146, de 6 de julho de 2015. Lei Brasileira de Inclusão da Pessoa com Deficiência. Estatuto da Pessoa com Deficiência. Diário Oficial da União - Seção 1 - 7 / 7/ 2015.

BRASIL. MEC. Plano Nacional de Educação PNE 2014-2024: Linha de Base. - Brasília, DF: Inep, 2015. 404 p.

BRASIL. MEC/Secretaria de Educação Especial. Política Nacional de Educação Especial na Perspectiva da Educação Inclusiva. Brasília: MEC/ SEESP, 2008.

BRASIL. MEC/SINAES. Instrumento de Avaliação Institucional Externa, Presencial e a Distância: transformação de organização acadêmica. Brasília: INEP, 2017. Disponível em: http://download.inep.gov.br/ educacao_superior/avaliacao_institucional/instrumentos/2017/ IES_recredenciamento.pdf. Acesso em 05 jan. 2020.

BRASIL. Secretaria de Direitos Humanos da Presidência da República. Educação em Direitos Humanos: Diretrizes Nacionais. Brasília: Secretaria Nacional de Promoção e Defesa dos Direitos Humanos, 2013. Disponível em: http://portal.mec.gov.br/index.php? 
Educação inclusiva nas políticas de avaliação

option $=$ com_docman\&view $=$ download\&alias $=32131-$ educacao - dh diretrizesnacionais-pdf\&Itemid=30192. Acesso em: 10 mar de 2018.

CLOT, Yves. A função psicológica do trabalho. $3^{\mathrm{a}} \mathrm{ed}$. Petrópolis: Vozes, 2006.

FURTADO, Júlio. Docência e alteridade. Congresso de Educação Básica: aprendizagem e currículo: COEB, 2012.

GATTI, Bernadete A. Sistemas de Avaliação Institucional: sistematização, interpretações e avaliação de informações. In: ARANA, Alba R. A. (org.). Os desafios da avaliação institucional: o papel da CPA. Curitiba: CRV, 2014. 124p.

GOIÁS. Resolução CEE N. o7, de 15 de dezembro de 2006. Conselho Estadual De Educação. Disponível em: http://www.sgc.goias.gov.br/ $\begin{array}{llllllllllllllllllllllll}\mathrm{u} & \mathrm{p} & \mathrm{l} & \mathrm{o} & \mathrm{a} & \mathrm{d} & / & \mathrm{a} & \mathrm{r} & \mathrm{q} & \mathrm{u} & \mathrm{i} & \mathrm{v} & \mathrm{o} & \mathrm{s} & / & 2 & \mathrm{o} & 1 & 6 & - & \mathrm{o} & 2 & /\end{array}$ res_cee_nr_07_de_15_dezembro_2006.pdf Acesso em: 20/05/2020.

MONLEVADE, João. Para entender o FUNDEB. Ceilândia: Idéa Editora, 2007.

RESENDE, Ana Paula Crosara de. Igualdade e não Discriminação. Artigo 5. In: A Convenção sobre Direitos das Pessoas com Deficiência comentada. Coordenação de Ana Paula Crosara de Resende e Flavia Maria de Paiva Vital. Brasília: Secretaria Especial dos Direitos Humanos, 2008. p. 164.

SANTOS, Boaventura S. Direitos Humanos: o desafio da interculturalidade. Revista Direitos Humanos, n.2, p.10-18, jun. 2009. Disponível em: http://www.boaventuradesousasantos.pt/media/ Direitos\%20Humanos_Revista\%20Direitos\%20Humanos2009.pdf Acesso em: 10 mar. 2018.

SANTOS, Thiffanne. P; REIS, Marlene. B. F. A formação docente na perspectiva da educação inclusiva. Travessias (UNIOESTE. Online), v. 10 N 02, p. 330-344, 2016. Disponível em < http://e-revista.unioeste.br/ index.php/travessias/article/view/13835>. Acesso em o6 jul. 2019

SCRIVEN, Michael. Avaliação: um guia de conceitos. Tradução de Marília Sette Câmara. Rio de Janeiro/São Paulo: Paz e Terra, 2018. 
SKLIAR, Carlos. A educação e a pergunta pelos Outros: diferença, alteridade, diversidade e os outros "outros". Ponto de Vista, Florianópolis, n. 05, p. 37-49, 2003. Disponível em: https:// periodicos.ufsc.br/index.php/pontodevista/article/view/1244. Acesso em 10 mar. 2018.

UNIVERSIDADE Estadual de Goiás (UEG). Plano de Desenvolvimento Institucional, 2009-2019. 


\section{Inclusive education in the policies of Institutional evaluation: reflections in the context of the State University of Goiás}

RESUMEN: The article is about the national and state guidelines for inclusive education in higher education and its impact on the planning, evaluation and results of the institutional self-assessment carried out at the State University of Goiás. The general objective was to verify the alignment between the principles of inclusive education and the institutional evaluation policies, consolidated in the Institutional Evaluation Report. The question was not formulated as a problem: how are the Special Education guidelines from the perspective of inclusive education reflected in the internal evaluation practice at the State University? In an attempt to make criticisms and point out suggestions, the study carried out applied the documentary analysis methodology of the Consolidated Three-Year Cycle Self-Assessment Report (UEG, 2015-2017) produced by CPA / UEG based on the PDI (UEG / 2010-2019).

PALABRAS Clave: Special Education. Inclusive education. Evaluation Policy. Self-evaluation.

\section{Diessyka Fernanda MONTEIRO}

Professora universitária (Fasseb/Faclions), Mestranda em Educação, Linguagem e Tecnologia pela Universidade Estadual de Goiás (UEG). Graduada em Letras (habilitação em Português) pela Universidade Federal de Goiás (2010). Especialista em Linguística pela Faculdade AVM (2016). Especialista em Teologia Sistemática pela Faculdade FAIFA (2015). E-mail: professoradiessyka@gmail.com.

Yara Fonseca de Oliveira e SILVA

Professora universitária (UEG), Doutora em Políticas Públicas, Estratégias e Desenvolvimento (UFRJ). Professora do Programa de Pós-Graduação Interdisciplinar em Educação, Linguagem e Tecnologia da Universidade Estadual de Goiás - PPGIELT - UEG - GO yarafonsecaso9@gmail.com. 